\title{
Male gender role strain as a barrier to African American men's physical activity
}

\author{
Derek M. Griffith, \\ University of Michigan, School of Public Health \\ Katie Gunter, and \\ University of Michigan, School of Public Health \\ Julie Ober Allen \\ University of Michigan, School of Public Health
}

\begin{abstract}
Despite the potential health consequences, African American men tend to treat their roles as providers, fathers, spouses, and community members as more important than engaging in health behaviors such as physical activity. We conducted 14 exploratory focus groups with 105 urban, middle-aged African American men from the Midwest to examine factors that influence their health behaviors. Thematic content analysis revealed three interrelated barriers to physical activity: (a) work, family, and community commitments and priorities limited time and motivation for engaging in physical activity; (b) physical activity was not a normative individual or social activity and contributed to men prioritizing work and family responsibilities over physical activity; and (c) the effort men exerted in seeking to fulfill the provider role limited their motivation and energy to engage in physical activity. These findings highlight the need for physical activity interventions that consider how health fits in the context of men's overall lives.
\end{abstract}

Over the last decade, obesity has increased significantly among men and particularly among African American men (Flegal, Carroll, Ogden, \& Curtin, 2010; Kumanyika, et al., 2008). While the prevalence of obesity is higher in African American women than men, nearly $40 \%$ of African American men ages 40 and older are obese (Flegal, Carroll, Ogden, \& Curtin, 2010; Kumanyika, et al., 2008). Researchers have consistently identified physical activity as one of the most important factors associated with reducing the chances of becoming or remaining obese. African American men have higher rates of developing and dying from many conditions and diseases associated with obesity and physical inactivity than white men, white women and African American women (Warner \& Hayward, 2006). Although men tend to engage in more physical activity than women, both men and women struggle with obesity and find it difficult to incorporate regular physical activity in their lives

\footnotetext{
${ }^{1}$ This manuscript was supported in part by grants from the American Cancer Society (MRSGT-07-167-01-CPPB), the Michigan Center for Urban African American Aging Research (5P30 AG015281), the Cancer Research Fund of the University of Michigan Comprehensive Cancer Center, and by the Center on Men's Health Disparities, University of Michigan, School of Public Health. Its contents are solely the responsibility of the authors and do not necessarily represent the views of our funders or the University of Michigan.
} 
(Dishman, 2001). Half of African American men in the U.S. report no leisure time physical activity (Ward, et al., 2004).

Despite the need to reduce men's rates of obesity and physical inactivity, the majority of studies on the treatment and prevention of obesity, unhealthy eating, and sedentary lifestyles have included samples that were predominantly female (Kumanyika, et al., 2008). More specifically, physical activity and physical fitness interventions focused on African Americans have tended to include less that $30 \%$ men (Whitt-Glover \& Kumanyika, 2009). This suggests that the social, cultural and conceptual significance of male gender has not received adequate attention as a barrier to physical activity for men in general, or African American men in particular. Gender roles, responsibilities and lives have been identified as barriers to physical activity for women (Belza \& Warms, 2004; Eyler, et al., 1998; Malpede, 2007; Segar, Eccles, \& Richardson, 2008) but not for men. Identifying the gendered factors that may be barriers to physical activity for men (Bopp, et al., 2006) is a critical, yet underdeveloped, area of research. Many of the gendered barriers to men's health behavior may have to do with how men psychologically and behaviorally cope with being in an environment where they are under economic, social and cultural pressure to fulfill key social and cultural roles (Griffith, et al., 2007; Watkins, Walker \& Griffith, 2009; Williams, 2003).

Role strain is a theoretical framework that describes the personal and social coping strategies people use to manage and mitigate social inequities (Bowman, 1989, 2006). Originally developed in the 1970s and 80s, role strain has typically been conceptualized as the ways in which men conform to a single standard of masculinity: white men (Levant \& Pollack, 2003; Smiler, 2004). Despite the contradictory and inconsistent demands of masculine ideologies and male gender norms, theories and measures have conceptualized male gender role strain as a stressor (Smiler, 2004). The strain men experience is rooted in how they think about gender-typed behavior, their degree of discomfort in particular genderrole situations and their concern about and actual violations of male gender role expectations or gendered behaviors that are associated with social and cultural roles (Thompson \& Pleck, 2005). Most theories and measures of male gender role strain and male gender norms tend to include broad stereotypes of men and samples of predominantly white college students, and tend not to be used in studies of men's health behavior, particularly African American men's health behavior (Levant \& Pollack, 2003; Wade, 2008). Role strain theories in general have been criticized for not considering the social, cultural and developmental contexts of gender roles (Robertson, 2008).

Bowman's (Bowman, 1989, 2006) conceptualization of role strain addresses many of the critiques of other gender role strain theories and it considers the unique stressors facing African American men across the life course. Bowman's conceptualization of role strain characterizes masculinity, not simply as a universal and abstract notion, but as a stressor that becomes more or less salient in different phases of men's lives, social and economic conditions, and in relationship to different behaviors. This theory highlights that men's perceived attitudes, gender norms, and gender roles are influenced by local and national gender norms, regardless of race or ethnicity, and the unique local and national racial and ethnic gender norms for African American men of a certain age and phase of life (Bowman, 1989, 2006). Despite its advantages over other conceptualizations of role strain, Bowman's 
theory of the relationship between male gender role strain and African American men's physical health and health behavior has not been tested.

Particularly during their middle-adult years, African American men's evaluations of how well they feel they are fulfilling the roles of provider, husband, father, employee, and community member are fundamental aspects of their identities (Bowman, 1989; Hammond \& Mattis, 2005). From approximately ages 34-60 (Erickson, 1980; Newman, 2009), fulfilling the provider role is the major focus of this phase of life (Bowman, 1989; Cazenave, 1979, 1981). Despite the changes and flexibility in gender roles over time, the family provider role continues to be a salient aspect of African American men's identity (Bowman, 1989).

African American men tend to face some unique challenges in seeking to fulfill the provider role. Middle-class African Americans when compared with middle-class Whites, however, have markedly lower levels of wealth, and are less likely to be able to translate similar levels of income into desirable housing and neighborhood conditions (Williams, 2003). At every level of education, African American men earn lower levels of income than White men. African American men's socioeconomic status also is positively related to stress, though socioeconomic status is inversely related to stress for African American women (Watkins, Walker \& Griffith, 2009; Williams, 2003). Such findings highlight some of the unique challenges African American men face in trying to fulfill the family provider role.

The goal of this paper is to utilize Bowman's theory of African American male gender role strain to explore how gendered social and cultural roles may act as barriers to African American men engaging in regular physical activity. African American men's efforts to fulfill the provider role occur in an economic and structural environment that constrains their ability to adequately meet the financial needs of their families. As African American men struggle to resolve differences between their capacity and desire to fulfill key male roles in their families and communities, we hypothesize that they may be less likely to engage in behaviors that promote their individual health, particularly physical activity. In this paper, we consider the social, cultural, life stage and economic contexts that influence African American men's role strain as barriers to recommended levels and intensity of physical activity.

\section{Methods}

\section{Setting}

This study took place in Flint and Ypsilanti, two cities located in southeastern Michigan. Flint and Ypsilanti are in the fourth and fifth largest metropolitan statistical areas in Michigan, respectively (U.S. Census Bureau, 2009a). Flint is the chief urban area in Genesee County, and Ypsilanti is located next to the larger and more affluent city of Ann Arbor (U.S. Census Bureau, 2009b). Both cities have a high percentage of African Americans, but the surrounding areas are predominantly White (U.S. Census Bureau, 2009b). Both cities rank below the state and the country on most socioeconomic indicators, and both have unemployment rates higher than state and national averages (U.S. Census Bureau, 2009b; Department of Labor, 2009). African American men in these cities 
experience elevated death rates for diseases associated with physical inactivity compared with the state and nation: in Genesee County, African American men experience higher death rates than African American women and white men and women for heart disease, stroke, diabetes mellitus, and cancer; in Ypsilanti, African American men have higher death rates than African American women and white men and women for heart disease and cancer (Michigan Department of Community Health, 2000; National Center for Health Statistics, 2001).

\section{Study design}

The data examined for this paper are derived from a larger study called Men 4 Health $(M 4 H)$, which is a five-year research project sponsored by the American Cancer Society. M4H is designed to learn about and enhance urban, African American men's health by systematically developing and implementing a culturally, contextually and gender sensitive intervention to increase physical activity and healthy eating and reduce obesity. Exploratory focus groups were conducted with African American men to examine individual and collective perspectives on the social, cultural, and economic barriers and facilitators to African American men's health behaviors associated with physical activity. Of particular interest was how intersections of race/ethnicity, gender, life stage, and social and environmental contexts influenced men's health behaviors.

The focus groups were designed to have a relaxed, casual atmosphere to facilitate open discussion among the participants and between participants and facilitators. The groups lasted about two hours and included a meal, the completion of consent and demographic forms, and an audio taped, in-depth discussion. The guided, semi-structured focus groups proceeded from general to more specific questions, with extensive probing for greater detail. Some of the questions were: What influences how much physical activity you get? For you or other African American men age 35 and older, what makes it easier to be physically active? What makes it more difficult to be physically active? The focus group protocols, forms, and overall study were reviewed by the University of Michigan Institutional Review Board. Trained African American male group facilitators from the two cities, who were in the same age group as the study participants, led the groups. They were assisted by observers who took field notes to document group dynamics and track the comments of individual speakers. Unique identifiers were assigned to each participant to ensure anonymity.

\section{Recruitment}

Focus group participants were recruited by snowball sampling via word-of-mouth, fliers, and the extensive social networks of the project's outreach staff and partner organizations. The project's outreach staff were African American men from our focus population who were active members of their communities. They strategically attended events and contacted organizations, groups, and informal social networks serving the population of interest to raise awareness about the study, distribute flyers, and recruit a diverse sample of men meeting our eligibility criteria to take part in the study. Each participant received a meal and the equivalent of $\$ 20$ in incentives for participating in a focus group. 


\section{Study Participants}

One hundred and five African American men participated in 14 focus groups: ten groups with a total of 63 men from Flint, MI; and four groups with a total of 42 men from Ypsilanti, MI. Data were collected between July 2008 and March 2009. We examined the data derived from the entire sample for this analysis (see Table 1 for study participant characteristics).

\section{Data Analysis}

The focus group recordings were transcribed verbatim and entered into the qualitative data software package, ATLAS.ti, 5.2 (Scientific Software Development, Berlin, 1998). The unique identifiers and observers' notes were used to link each participant's demographic data to his discussion comments. Our data organization process was similar to the methods used by Griffith and colleagues (Griffith, et al., 2008; Griffith, et al., 2007; Griffith, Allen, \& Gunter, under review). Each focus group transcript was chunked into segments of text that represented distinct concepts that conveyed their original meanings apart from the context of the complete transcript. Selected transcripts were reviewed in order to inductively ascertain recurring patterns that emerged from the transcripts and topics related to the research questions guiding the $M 4 H$ project. This process yielded a codebook of phenomenological concepts (codes) chosen to enhance the ease and reliability of the assignment of codes to the text segments. A team of university-based researchers trained in qualitative data research methodology and the use of this codebook assigned codes to the focus group transcripts.

During the iterative process of reviewing the coded data, compelling themes related to the influence of gender roles and responsibilities on men's lives and participation, or lack thereof, in physical activity emerged. For this paper, we focused primarily on examining one code from our codebook-Gender-in order to learn about gendered factors influencing urban, African American men's physical activity.

Gender was a broad code used to identify and capture all mention of gender, masculinity, differentiating between men and women, gender stereotypes, assumptions related to gender, or generalizations based on gender that may have had some relation to health behavior, particularly physical activity. Due to the breadth and comprehensiveness of text segments captured with this code, we felt it to be appropriate and adequate for a thorough analysis of how men discussed issues associated with male gender. Quotes that addressed issues of gender indirectly or through implication, such as when the focus group participants did not specifically articulate the connection between a statement and gender, were not coded with the Gender code or included in this paper. For example, we did not include comments about division of labor in the household between men and their spouses or how men may serve as models for younger men's health behavior. Although gender roles and socialization are complex phenomena and many of the focus group participants alluded to ways in which gender influenced their health, we chose not to include this material in this paper because it would have required that we interpret or make assumptions about the men's statements that were not explicitly stated. 
Each segment of text assigned the Gender code also was linked to all the other codes assigned to that text, the unique identifier of the speaker, the geographic location and date of the focus group, the overall question, and any other stimuli (prompts, comments of other participants) that appeared to influence the individual's statement. Each member of the research team used highlighting and margin notes to: a) summarize themes within the document, often using in vivo restatements of the data; and b) document potential questions, connections, underlying themes, and possible implications of the text for further analysis, and suggest questions to pose during the member checking groups. Comparison margin analysis was used to ensure consistent interpretation of the statements. We created a document that roughly summarized the concepts contained within the Gender data chunks and recorded the frequency of focus groups and men who discussed this topic to ensure broad representation.

The authors collectively identified nine distinct, yet often overlapping, themes that emerged from the segments of test assigned the Gender code on how the men perceived gender to influence their physical activity. The nature of these themes did not differ between the comments of focus group participants from Flint and Ypsilanti, so we did not include geographic comparisons. This paper focuses on five themes representing male roles and associated stressors and strains that inhibit greater participation in physical activity: men's time was filled by commitments associated with male roles and responsibilities; men prioritized the roles of father, spouse, community member, and particularly provider/ employee over other aspects of their lives, including their individual health; social and cultural norms, many developed during childhood, about the importance of work; social and cultural norms around physical activity; and employment-related strain, exhaustion and stress coping strategies. These five themes contained the greatest number of quotes, representing $70 \%$ of the Gender text segments. The other quotes were distributed among codes that had little to do with gender roles and more to do with a diverse and disconnected array of beliefs, attitudes and behaviors associated with male gender. For example, we did not include references to men 'not wanting to be told what to do'; beliefs about 'what men should be able to do' to promote their own health; or men's knowledge about the health benefits of physical activity.

Following our thematic analysis, data organizing and analytic focus, we engaged in two processes to validate the importance and accuracy of the themes we detected. We repeated the process of summarizing, comparison coding, and reviewing seven other codes that were closely associated with the themes that emerged from our analysis of the Gender data and that frequently overlapped with the Gender code: discrimination, money, social and cultural norms, roles in the family, roles at work, motivation/prioritization, and stress. There were three goals of this process: (1) to make certain we captured all the data chunks related to Gender; (2) to determine if the data from the other codes contained additional Genderrelated themes that had not emerged from our analysis of the Gender code; and (3) to discern whether there was any data contradicting or refining the themes we identified. This process confirmed that the Gender code had been assigned consistently and comprehensively and did not produce any additional data for inclusion in our analysis. We also conducted two member checking groups (Creswell, 1998; Lincoln \& Guba, 1985) with men from our 
population of interest to ensure that the research team's interpretations of the data were congruent with the experiences and perceptions of members our sample population. These groups helped to refine our interpretation of the data and confirmed the congruence of our analysis with men from our population of interest.

\section{Results}

For the urban African American men that participated in our focus groups, the commitments, prioritization, expectations, and the physical and psychological demands associated with fulfilling male gender roles were central factors that affected whether and how frequently they engaged in physical activity. The focus group participants generally recognized the health benefits of engaging in physical activity and the potential negative health consequences associated with a sedentary lifestyle. Many of the participants said they would like to be more physically active, but they faced a number of barriers to engaging in physical activity that were associated with a strong desire to fulfill key socially and culturally defined gender roles of a worker, provider, spouse, father, and community member.

The data are presented in three sections, collapsing the five previously identified themes for fluidity of description. These sections describe interrelated barriers to physical activity associated male gender role strain: (a) work, family, and community commitments and priorities limited time for and were considered more important than engaging in physical activity; (b) social and cultural norms and expectations promoted men's prioritization work and other responsibilities, whereas physical activity was not a normative individual or social activity; and (c) the effort men exerted in seeking to fulfill the provider role limited their energy to engage in physical activity. These themes are discussed below and include representative quotes from participants.

\section{Time Commitments and Priorities of Roles and Responsibilities Limit Physical Activity}

While men viewed physical activity as beneficial, one of the most basic barriers they faced was trying to fit physical activity into their lives. Busy work schedules, long work days, commuting, multiple jobs, and other work-related responsibilities constrained their ability to engage in physical activity to be physically active. One focus group participant who was under some financial strain and supporting his elderly mother explained,

I think that, for myself, it's just a matter of having time available [for physical activity]. When I'm working second shift, I don't really have the whole [day]. By the time I get up out of the bed, it's time to get ready for work. And then by the time I get off work, there's nothing really available.

In addition to the challenges associated with busy work schedules, most men in our focus groups reported that they had busy social lives. They sought to participate in activities with their families - children, grandchildren, spouses, and extended family - and in the community - churches, fraternities, or volunteer organizations. The men described themselves as dedicated to being active participants in their children's lives, their families and their communities, which left little time for engaging in physical activity. As one 43 year old participant described, 
So I'd say for the majority of black men—I'm saying myself, my brothers, my neighbors-we're just caught up in the lifestyle working every day. And when you come home, you've got to either cook or help your wife to cook or deal with some issue, you know, with one of the children or grandchildren. So, you know, the 30 minute workout on the step master or going to the gym consistently is not something that, you know, is a high priority.

Similarly, in the context of time devoted to work and family obligations, one 53 year old man described the difficulty he faced balancing a long commute with family and community responsibilities:

I think the rigors of career, community activities, and the family. Once you kind of satisfy those activities, there really isn't much time left in the day for a lot of physical activity. I know, for me, that's one of my challenges. I commute 110 miles a day, to and from work. I'm active with my fraternity and a youth group. And then still trying to spend time with the wife and, when the kids are home, with my kids. And when you add up the day, there's nothing left.

The men in our focus groups placed considerable value on being spouses, fathers and community members. Work, family and community activities constituted a considerable amount of men's time, efforts, and energy, resulting in little attention to or engagement in physical activity. As one focus group participant explained, “... once you go home, and you say I'm going to get my workout stuff, and then you see things that you have to do, you know, at your house. That workout tends to get placed on the backburner." In the context of describing how spending time with his young daughter and responsibilities with work limited his time for physical activity, another participant stated, "Sometime I can get it [some physical activity] in, but with a little one at the house and a side businesses and things, I don't have the time to get out there and do like I should." These comments suggest that men struggle to find the time to engage in physical activity, though they recognize its value.

The African American men in our focus groups described two lifestyle-related barriers to physical activity - busy schedules and life priorities. Their busy schedules were driven by efforts to be actively involved in the workforce, at home, and in their community. The participants described having a strong desire to fulfill their roles as workers, fathers and community members, which they saw as more important than engaging in physical activity. The next section delves into social and cultural norms that shaped these priorities in men's lives and why physical activity and their own health were valued so much less.

\section{Social and Cultural Norms about Work and Physical Activity}

For some of the men, the emphasis placed on work and the importance of work in their families during their formative years contributed to them prioritizing work over health throughout much of their adult lives. Prioritizing work over physical activity appears to be a behavior learned and reinforced by the familial and community context in which they grew up. One 46 year old man described the priorities in the lives of African American men as, “... our hierarchy of responsibilities. And the first two are usually family and work." He also described that he learned these priorities, values and behaviors in the context of his 
family: “... I came from a family in which my father worked, my mother worked. So, naturally that kind of rubs off on you as it relates to working. It has to be a priority. And, you know, providing for your family." This hierarchy seemed to be both internalized by the men and reinforced by family and community members' expectations of what men's priorities should be.

Men described being physically active and taking care of their health as less imperative than fulfilling other obligations in their lives. As a focus group participant with two young children described:

We commit ourselves to work. We commit ourselves to family. We commit ourselves to the community. I mean, there's always somebody pulling at us. It's always something that we have to do. So, by the time you get to the point where you start thinking about yourself, it's a little too late. It's a little too late. And I think that's the reason why we get caught up, as far as not really taking care of ourselves, health-wise, not necessarily really exercising the way we want to or we need to, because we're too busy taking care of our kids' kids.

The men appeared to value their ability to fulfill the socially and culturally important roles of employees, parents, spouses, and community members more than their individual health. Some even described exercise as a luxury for African American men. One participant stated:

... exercise, that wasn't a part of surviving. You know what I mean? I mean, different places, they could exercise and they got schools and the whole communities. That's all they do, that's all they do is exercise. But African American men, you see. That wasn't no luxury. That's my point.

This participant, who seems to view exercise as a luxury, also indicated that he was under considerable financial stress and noted that he had multiple health problems associated with obesity and a sedentary lifestyle.

Although there was a general consensus that work was a higher priority than their health, some of the men recognized that their lives lacked "balance" because they would like to incorporate physical activities into their regular lives. For example, one 53 year old who is physically active once a week described the challenge of meeting competing priorities this way:

I, for one, have an unhealthy balance, and it's because even though I retired from one company, and I've taken a job at another company. There's still this bit of career drive and motivation that you have in that. It has me out of balance, because I take that... and then I take a couple commitments I have to community activities...extremely serious. And so, and then I put my family in there, and I don't have the right balance.

While some recognized that they wanted and even needed to be more active to maintain or improve their health, this awareness did not necessarily lead to changes in men's lifestyles.

For many of the African American men in our focus groups, physical activity was not viewed as a normative part of family and community social activities either growing up or 
currently. As one 53 year old explained, "We don't have built in physical activities that we do as a family.... We tend to maybe do more entertainment type things. We'll go to the amusement park and maybe sit on the bench while the kids ride... I think it's a cultural thing. If we're not brought up that way, we tend to not maybe gravitate to a lot of the exercise type things that the family can do." Several men suggested that if physical activity was not incorporated into other aspects of their lives, such as their family or work life, they were unlike to do it. The same participant quoted above went on to say, "And I think one of the things is that we put a premium on our work, as opposed to our health and our family."

Social and cultural norms shaped the attitudes and behaviors of the study participants regarding the emphasis and value placed on men's roles at work and home and the lack of attention paid to physical activity and men's personal health. This seems to reflect, in part, the influence of their families and expectations in their communities during their formative years and contemporary lives. Physical activity, particularly during leisure time, seemed to be viewed as a luxury and relatively unimportant compared to fulfilling work, family and community roles and responsibilities. Participants seemed to find it difficult to identify ways of incorporating physical activity in family activities, partly because it was not a social or cultural norm, and partly because work tended to supersede other aspects of their lives. The fact that work was their highest priority highlights how important the provider role was in men's lives.

\section{The Stress and Exhaustion of Striving to Fulfill the Provider Role}

Fulfilling the provider role seemed to be at the top of men's list of priorities and a major obstacle to engaging in greater levels of physical activity on multiple levels. Striving to meet family needs, fulfill financial needs and obligations, and manage work and career success presents chronically stressful challenges. One participant who reported being under a great deal of financial strain described the implications of his effort to fulfill the provider role this way:

Career-wise, if you're looking to work as hard as you're working to move forward, and then you get slighted..., stress creeps in. So, now you got to work double time to try and get where you want to go. And at the same time, ... college still need to be paid for, food still needs to be in the house, bills still need to be paid. I'm not even talking about physically, just mentally, by the time I get home, I'm drained.

Not only did these men find these life circumstances and priorities stressful, they often talked about experiencing physical and mental exhaustion. Part of the reason men reported feeling so stressed and tired was because they rarely had a break in the transition from one set of responsibilities, usually work, to another, taking care of family and community responsibilities. One participant who lived with several members of his extended family described his strategy of trying to fulfill his role as a provider for the family and prioritizing work and family needs:

I think it has more to do with the survival mode. Typically, most of the black men I know right now, if they're lucky to have a job, they're either working a full-time job or a job and a half. And between working a job, getting ready to go to work and 
coming home, dealing with the family, a consistent 30 minute exercise program is not a high priority.

The term "survival mode" suggests that men like this one felt as though they were just 'getting by' and keeping their lives from falling apart. In this context of working long and stressful hours, not only is physical activity a low priority, but alternative activities may provide outlets for coping with stress. According to a sedentary 47 year old man with two children at home:

I think that most guys, if they're working, nine times out of ten they're going to go home, eat, and go to bed from being tired from their job. You may get out in your yard or do something, you know, or even do some physical. But the majority, most guys, when they get off work, they want to sit down, and maybe drink a beer, and eat and go to bed. And get ready for the next days. Doing physical [activities] or trying to lift some weights... that's the last thing on their minds.

While physical activity can be an effective way to relieve stress, the African American men in our focus groups generally reported seeking other sources of stress relief-resting (relaxing or sleeping), drinking alcohol, or eating - to deal with the strain of fulfilling provider and other roles within their families and communities.

The stress and exhaustion these men experienced resulting from fulfilling provider and other key family and social roles seemed to be major obstacles inhibiting them from participating in physical activity more regularly. Not only did they report the stress and strain of prioritizing work, but these African American men noted how physically and mentally draining it was to seek to be good providers, fulfill family roles, and contribute to their communities. The exhaustion they reported seemed to be a barrier to them engaging in physical activity. They also had other strategies for coping with stress that further reduced their motivation to consistently engage in physical activity.

\section{Discussion}

In this study of the relationship between male gender role strain and physical activity, efforts to fulfill the roles of provider, father, spouse, and community member were critical barriers to men being more physically active. Specifically, three aspects of role strain emerged from the data as barriers to physical activity for these urban, Midwestern, middle-aged African American men: (1) the time commitments and prioritization of employment, family, and community responsibilities reduced, limited, and constrained men's participation in and motivation to engage in physical activity; (2) work and family were perceived as more important than physical activity and other aspects of men's lives; and physical activity was not a normative part of African American men's individual, family or community lives or activities. Finally, (3) the stress and exhaustion of seeking to fulfill employment, family, and community roles decreased African American men's likelihood of being active, and their strategies for coping with stress, stressors and strains typically did not include physical activity.

Consistent with other research (Diemer, 2002), we found that employment, work, and career aspirations were more important to these middle-aged African American men than their 
physical health. Adhering to busy work schedules, striving for success in their careers, seeking to fulfill the role of financial provider, family time and responsibilities, and being active in their community were critical priorities that were congruent with their phase of life and more valued than engaging in physical activity. These activities, responsibilities, and goals also presented barriers to participation in physical activity because they took up a great deal of the men's time and energy. Given the economic and structural barriers that present constraints for many African American men, the time, effort, and stress associated with fulfilling social and cultural roles may contribute, in part, to men allocating little time and attention to physical activity.

Family emerged as central priority in these African American men's daily lives. Participants sought to be good spouses and fathers, and these roles were considered more important than being physically active. As has been found in previous research (Hammond \& Mattis, 2005; Hunter \& Davis, 1992), the African American men in our study constructed their identities and notions of masculinity in relation to family members and others, and the men's ability to be responsible and accountable for and to them. The way in which men from our focus groups organized their priorities were developed during their upbringing and reinforced by current family and community member expectations (Griffith, et al., 2007; Griffith, Allen, \& Gunter, under review; Ornelas, et al., 2009). The way in which these African American men prioritized their social and cultural roles and their health is congruent with a relational construction of masculinity (Hammond \& Mattis, 2005; Hunter \& Davis, 1992), and highlights that African American men view themselves in relation to their ability to fulfill key social and cultural roles. Adhering to culturally-specific gender role expectations presents challenges that African American men must navigate (Hunter \& Davis, 1994) in order to initiate and maintain a healthy lifestyle that would include regular moderate and vigorous physical activity.

The importance of family and community to men in our focus groups suggest that exploring what health means to African American men may have to include life stage-appropriate roles and goals. The difficulty African American men face in seeking to fulfill provider role obligations has been shown to compromise family satisfaction (Orbuch \& Custer, 1995) as well as men's psychological health and overall well-being (Bowman, 1989). Ravenell and colleagues (2006) found that African American men may define health broadly and in relation to other aspects of their lives that may have little to do directly with their own individual health. African American men have conceptualized being "healthy" as being able to fulfill social roles, such as holding a job, providing for family, protecting and teaching their children, and belonging to a social network (Ravenell et al., 2006). Similarly, many of our focus group participants seem to view health as a part of who they are and how they perform in other parts of their lives, not necessarily health promoting behaviors. If men are focused on fulfilling key roles in their lives yet struggle to achieve success in the family provider role, it is not surprising that physical activity may become a lower priority in their lives.

Barriers to creating and maintaining healthy lifestyles and achieving success in key life roles warrants some strategy for coping with chronic role strains (Bowman, 1989). Although engaging in physical activity has been associated consistently with better psychological 
health, the men in our focus groups rarely reported physical activity as a strategy for stress management. Our participants described stress management activities that promoted relaxation or "non-brain activity" after work or during other leisure time. Leisure time also was considered time to spend with family, not for pursuing individual interests or needs such as engaging in physical activity.

\section{Limitations}

Although it is critical to gather and explore African American men's perspectives on the relationship between their social and cultural roles and rates of physical activity, several limitations of this research should be considered. Our goal was not to disseminate findings that are broadly generalizable, but to describe barriers to physical activity that can be used to refine theories that describe health behavior and inform future interventions with middleaged adults, particularly African American men. Qualitative research methods and data analysis techniques often elicit concerns about the validity and reliability of the data. Our data analysis strategy involved a systematic process of coding scheme development, refinement, and quote attribution. Some perspectives were lost in the data coding, analysis, and reporting processes, as themes that were not articulated by at least a few focus group participants were not included in the paper. While our procedures captured the strongest and most prevalent themes, they may have eliminated unique perspectives voiced by a minority of respondents. In order to diminish this problem, the authors conducted member checking groups with men from the population of interest to assess the validity of the data findings (Creswell, 1998). Despite the challenges of qualitative research, there are many benefits of this methodological approach that were particularly vital in this project. The thick description of qualitative methods tap into many different voices and perspectives in participants' own words. This study design enabled the recognition of patterns, as well as subjective interpretations and perceptions of causality (Banyard \& Miller, 1998).

The high rate of our focus group participants reporting at least the minimum amount of physical activity recommended by the U.S. Department of Health and Human Services also seems inconsistent with the contents of our focus group discussions and the high prevalence of obesity among our participants. We defined physical activity more broadly than leisuretime physical activity, and included such activities as yard work, vacuuming, and gardening. Because we captured a broader range of activities than is typically reported in research studies on physical activity, our rates of physical activity may seem higher than expected. Also, the current recommendations require individuals to effectively distinguish between moderate and vigorous physical activity, which is then used to approximate energy expenditure and other physiological effects; it is possible our participants overestimated their intensity of physical activity, which could have significantly inflated their reported rates of physical activity.

\section{Implications for Interventions}

African American men have been considered disinterested in their own health (Ravenell et al., 2006), when it may be that they have prioritized social and cultural roles over their individual physical health. A lack of focus on their own physical health is not synonymous with a lack of interest in health, however. Our findings suggest that middle-aged African 
American men's low prioritization of physical activity is socially and culturally congruent with their phase of life and is perceived to be reinforced by family members, community expectations and broader social norms.

Consequently, interventions to increase physical activity in African American men may need to help men, and key people in their daily lives, find ways to integrate physical activity into their lives such that it facilitates, not competes with, valued social and cultural roles and expectations. This may include working with spouses, family members and community members to provide more support for African American men's participation in physical activities, and to change social and cultural norms to increase the amount of physical activity that African Americans engage in during leisure times and social events.

While the African American men who participated in our focus groups placed a lower value on physical activity, it is not clear how these findings apply to their conceptualizations of their overall health or other health behaviors. Placing a lower value on physical activity, however, is not the same as placing a lower value on overall health. Consistent with the notion of John Henryism (James, Hartnett, \& Kalsbeek, 1983), African American men may cope with chronically stressful economic and social conditions at the expense of their personal health. For some men, they may not see physical activity and overall health as interrelated.

African American men's inadequate rates of moderate and vigorous physical activity and other health behaviors occur in the social and structural context of their lives and lifestyles (Marcus, et al., 2006; Yancey, Ory, \& Davis, 2006). Interventions to improve middle-aged African American men's health behaviors might begin by recognizing men's life priorities, and working with them to determine how to more effectively incorporate and sustain a program of regular physical activity. As the men in our focus groups appeared to be participating in some physical activity, it may be necessary to address other factors that contribute to high rates of obesity and diseases associated with physical inactivity such as eating behaviors and stress. Future research should consider the relationship between African American men's life priorities, overall health, and other health behaviors.

\section{References}

Banyard VL, Miller KE. The powerful potential of qualitative research for community psychology. American Journal of Community Psychology. 1998; 26(4):485-505.

Belza B, Warms C. Physical activity and exercise in women's health. The Nursing Clinics of North America. 2004; 39(1):181-193. [PubMed: 15062735]

Bopp M, Wilcox S, Laken M, Butler K, Carter RE, McClorin L, et al. Factors associated with physical activity among African-American men and women. American Journal of Preventive Medicine. 2006; 30(4):340-346. [PubMed: 16530622]

Bowman, PJ. Research perspectives on Black men: Role strain and adaptation across the adult life cycle. In: Jones, RL., editor. Black Adult Development and Aging. Berkeley, CA: Cobb \& Henry Publishers; 1989. p. 117-150.

Bowman PJ. Role Strain and adaptation issues in the strength-based model: diversity, multilevel, and life-span considerations. Counseling Psychologist. 2006; 34(1):118-133.

Cazenave NA. Middle-income Black fathers: An analysis of the provider role. The family coordinator. 1979; 28:583-593.

Creswell, J. Qualitative Inquiry and Research Design. Thousand Oaks, CA: Sage Publications; 1998. 
Diemer MA. Constructions of provider role identity among African American men: An exploratory study. Cultural Diversity and Ethnic Minority Psychology. 2002; 8(1):30-40. [PubMed: 12092427]

Dishman R. Adherence to exercise and physical activity. QUEST. 2001; 53:277-278.

Erickson, EH. Identity and the Life Cycle. New York: Norton; 1980.

Eyler AA, Baker E, Cromer L, King AC, Brownson RC, Donatelle RJ. Physical activity and minority women: a qualitative study. Health Education \& Behavior. 1998; 25(5):640-652. [PubMed: 9768383]

Flegal KM, Carroll MD, Ogden CL, Curtin LR. Prevalence and trends in obesity among US adults, 1999-2008. Journal of the American Medical Association. 2010; 303(3):235-241. [PubMed: 20071471]

Friedenreich CM, Orenstein MR. Physical activity and cancer prevention: Etiologic evidence and biological mechanisms. Journal of Nutrition. 2002; 132(11 supl):3456-3464.

Gotay CC. Behavior and cancer prevention. Journal of Clinical Oncology. 2005; 23(2):301-310. [PubMed: 15637393]

Griffith DM, Allen JO, Zimmerman MA, Morrel-Samuels S, Reischl TM, Cohen SE, et al. Organizational empowerment in community mobilization to address youth violence. American Journal of Preventive Medicine. 2008; 34(3):S89-99. [PubMed: 18267207]

Griffith DM, Mason MA, Rodela M, Matthews DD, Tran A, Royster M, et al. A structural approach to examining prostate cancer risk for rural southern African American men. Journal of Health Care for the Poor and Underserved. 2007; 18(Supplement):73-101. [PubMed: 18065853]

Griffith DM, Allen JO, Gunter K. Social and Cultural Factors that Influence Whether Urban African American Men Go to the Doctor. Research on Social Work Practice. under review.

Hammond WP, Mattis JS. Being a Man About It: Manhood Meaning Among African American Men. Psychology of Men \& Masculinity. 2005; 6(2):114-126.

Hunter AG, Davis JE. Constructing gender: An exploration of Afro-American men's conceptualization of manhood. Gender \& Society. 1992; 6:464-479.

Hunter AG, Davis JE. Hidden voices of black men: The meaning, structure, and complexity of manhood. Journal of Black Studies. 1994; 25(1):20-40.

James SA, Hartnett SA, Kalsbeek WD. John Henryism and blood pressure differences among black men. Journal of Behavioral Medicine. 1983; 6(3):259-278. [PubMed: 6663614]

Kumanyika SK, Obarzanek E, Stettler N, Bell R, Field AE, Fortmann SP, et al. Population-Based Prevention of Obesity: The Need for Comprehensive Promotion of Healthful Eating, Physical Activity, and Energy Balance: A Scientific Statement From American Heart Association Council on Epidemiology and Prevention, Interdisciplinary Committee for Prevention (Formerly the Expert Panel on Population and Prevention Science). Circulation. 2008; 118(4):428-464. [PubMed: 18591433]

Levant, RF.; Pollack, WS., editors. A New Psychology of Men. New York: Basic Books; 2003.

Lincoln, YS.; Guba, EG. Naturalistic Inquiry. Beverly Hills: Sage; 1985.

Malpede CZ. Racial influences associated with weight-related beliefs in African American and Caucasian women. Ethnicity \& Disease. 2007; 17(1):1-5. [PubMed: 17274201]

Marcus BH, Williams DM, Dubbert PM, Sallis JF, King AC, Yancey AK, et al. Physical Activity Intervention Studies: What We Know and What We Need to Know: A Scientific Statement From the American Heart Association Council on Nutrition, Physical Activity, and Metabolism (Subcommittee on Physical Activity); Council on Cardiovascular Disease in the Young; and the Interdisciplinary Working Group on Quality of Care and Outcomes Research. Circulation. 2006; 114(24):2739-2752. [PubMed: 17145995]

Michigan Department of Community Health. Natality, Mortality, and Other Vital Statistics. Lansing, MI: Michigan Department of Community Health; 2000.

Newman, BM.; Newman, PR. Middle adulthood. In: Newman, BM.; Newman, PR., editors. Development Through Life: A Psychosocial Approach. 9. Belmont, CA: Wadsworth Centgage Publishing; 2009. p. 452-491.

National Center for Health Statistics. National Vital Statistics Report. US Department of Health and Human Services. 2001; 49(8) 
Orbuch TL, Custer L. The social context of married women's work and its impact on black husbands and white husbands. Journal of Marriage and Family. 1995; 57(2):333-345.

Ornelas IJ, Amell J, Tran AN, Royster M, Armstrong-Brown J, Eng E. Understanding African American men's perceptions of racism, male gender socialization, and social capital through photovoice. Qualitative Health Research. 2009; 19(4):552-565. [PubMed: 19201993]

Robertson, S. Theories of masculinities and health-seeking practices. Paper presented at the "Nowhere Man” Men’s Health Seminar; 2008. Retrieved from http://www.mensproject.org/issues/ stevespeech.pdf

Segar ML, Eccles JS, Richardson CR. Type of physical activity goal influences participation in healthy midlife women. Womens Health Issues. 2008; 18(4):281-291. [PubMed: 18468920]

Smiler AP. Thirty Year After the Discover of Gender: Psychological Concepts and Measures of Masculinity. Sex Roles. 2004; 50(1/2):15-26.

Thompson, EH., Jr; Pleck, JH. A New Psychology of Men. Vol. Ch 5. New York: Basic Books; 2005. Masculinity Ideologies: A Review of Research Instrumentation on Men and Masculinities. In R.F. Levant \& W.S. Pollack (Eds.); p. 129-163.

Wade JC. Masculinity ideology, male reference group identity dependence, and African American men's health-related attitudes and behaviors. Psychology of Men \& Masculinity. 2008; 9(1):5-16.

Ward E, Jemal A, Cokkinides V, Singh GK, Cardinez C, Ghafoor A, et al. Cancer disparities by race/ ethnicity and socioeconomic status. CA. 2004; 54(2):78. [PubMed: 15061598]

Warner DF, Hayward MD. Early-life origins of the race gap in men's mortality. Journal of Health and Social Behavior. 2006; 47(3):209-226. [PubMed: 17066773]

Watkins DC, Walker RL, Griffith DM. A meta-study of Black male mental health and well-being. Journal of Black Psychology. 2009 e-pub ahead of print November 242009.

Whitt-Glover MC, Kumanyika SK. Systematic review of interventions to increase physical activity and physical fitness in African-Americans. American Journal of Health Promotion. 2009; 23(6):S33-S56. [PubMed: 19601486]

Williams DR. The health of men: Structured inequalities and opportunities. American Journal of Public Health. 2003; 93:724-31. [PubMed: 12721133]

Yancey AK, Ory MG, Davis SM. Dissemination of physical activity promotion interventions in underserved populations. American Journal of Preventive Medicine. 2006; 31(4):82-91. 


\section{Table 1}

\section{Characteristics of Study Participants}

\begin{tabular}{|l|c|}
\hline Characteristic & Participants (n=105) \\
\hline Average Age & 54.8 years, range of 33-77 \\
\hline Married/in a relationship & $86.2 \%$ \\
\hline Children 18 and under in household & $31.4 \%$ \\
\hline Somewhat or very difficult to pay bills & $49.5 \%$ \\
\hline College graduates & $25.0 \%$ \\
\hline Meet recommended level of weekly physical activity (2.5 hrs. moderate/1.25 hrs. vigorous) & $75.3 \%$ \\
\hline Overweight or Obese (BMI of 25+) & $87.8 \%$ \\
\hline Report poor/fair health & $25.5 \%$ \\
\hline Have at least one chronic health problem & $71.2 \%$ \\
\hline Chronic health problems make it more difficult to be physically active & $16.0 \%$ \\
\hline
\end{tabular}

